\title{
THE ABSENCE OF ABNORMAL HAEMOGLOBINS IN 500 OUT-PATIENTS IN BRITAIN \\ BY
}

\author{
J. Q. MATTHIAS \\ From the Department of Pathology, St. Bartholomew's Hospital, London
}

(RECEIVED FOR PUBLICATION NOVEMBER 2, 1957)

The purpose of this investigation was to discover whether abnormal haemoglobins occur among the inhabitants of the British Isles, and, if so, to estimate their incidence. In view of the possible association between endemic malaria and the haemoglobinopathies, abnormal haemoglobins might well occur, malaria being previously endemic in parts of Britain.

The occurrence of haemoglobin $D$ has been reported in persons of partly British descent. It was found in a white North American family of partly Irish and English descent (Itano, 1951), again in a British family with Austrian and Spanish connexions (White and Beaven, 1954), and in a mulatto family where it was inherited from an English mother with no known foreign antecedents (Stewart and MacIver, 1956).

The sample investigated comprised 500 outpatients of St. Bartholomew's Hospital, London, referred for investigations requiring venous blood. The bearers of names judged not native to the British Isles were excluded. It was assumed that this group would constitute a fair sample of the British-born population of the four home countries.

The method of investigation used was paper electrophoresis, using veronal buffer at $p \mathrm{H} 8.6$ which would detect haemoglobins A, C, S/D, E, $\mathrm{G}, \mathrm{H} / \mathrm{I}, \mathrm{J}, \mathrm{K}$, and L. Suspicious slowing of the normal adult haemoglobin (A) band was followed by testing for the presence of foetal haemoglobin
(F) using the standard one-minute alkali denaturation test (Singer, Chernoff, and Singer, 1951).

Details of the electrophoretic technique are given by Lehmann and Smith (1954).

\section{Results}

The 500 cases examined yielded no abnormal electrophoretic patterns. All haemoglobins moved as a single band in the position of normal adult controls (AA pattern), and in no case was the foetal haemoglobin found to be abnormal.

\section{Conclusion}

It is possible that families with inherited abnormal haemoglobins exist in the more remote and isolated parts of the British Isles and would be detected in larger samples or samples from particular regions. However, none was found in this series. Thus abnormal haemoglobins either do not occur or are rare among the inhabitants of Great Britain.

I should like to thank Dr. H. Lehmann for suggesting this investigation.

REFERENCES

Itano, H. A. (1951). Proc. nat. Acad. Sci. (Wash.), 37, 775.

Lehmann, H., and Smith, E. B. (1954). Trans roy.. Soc. trop. Med. Hyg., 48, 12.

Singer, K., Chernoff, A. I., and Singer, L. (1951). Blood, 6, 429. Stewart, J. W., and MacIver, J. E. (1956). Lancet, 1, 23. White, J. C., and Beaven, G. H. (1954). J. clin. Path., 7, 175. 